\title{
Regulação do corpo feminino no almanaque de farmácia d'A Saude da Mulher
}

\author{
Beatriz Oliveira Santos ${ }^{1}$ \\ 0000-0001-7993-7135 \\ Idilva Maria Pires Germano' (iD 0000-0003-0062-9899 \\ 'Universidade Federal do Ceará, Fortaleza, CE, Brasil. pospsi@ufc.br
}

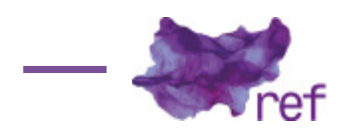

Resumo: Neste artigo são discutidos aspectos da regulação do corpo da mulher entre o final do século XIX e meados do XX, a partir da análise de uma seleção de números do almanaque de farmácia intitulado d'A Saude da Mulher. A publicação era uma das mais lidas pelas senhoras e veiculava o medicamento mais popular da indústria nacional voltado para sua saúde. Apresentava anúncios de medicamentos, horóscopos, ilustrações, cartas de leitoras, entre outras variedades. Envoltos de discursos morais, atuaram como dispositivo pedagógico, ensinando, inspirando e regulando comportamentos e modelando subjetividades, principalmente as das mulheres, que deveriam ser dóceis, boas mães, esposas e cuidadoras do lar. Este artigo argumenta como os almanaques atuaram como instrumentos de regulação, educando e medicalizando o corpo feminino, disseminando ideais de feminilidade e virilidade, família, saúde, higiene e progresso nacional.

Palavras-chave: corpo feminino; saúde da mulher; almanaques de farmácia; dispositivo pedagógico.

Regulation of the female body in the pharmacy almanac d'A Saude da Mulher

Abstract: This paper discusses aspects of the regulation of the female body, from the end of the 19th century to the mid 20th century, based on the analysis of a selection of numbers from the pharmacy almanac entitled d'A Saude da Mulher (Women's Health). The publication was one of the most read by the ladies of that time and advertised the most popular medicine in the national industry for their health. It featured medicines ads, horoscopes, illustrations, letters from readers, among other contents. Involved in moral discourses, they acted as a pedagogical device, teaching, inspiring and regulating behaviors and modeling subjectivities, especially those of women, who should be docile, good mothers, wives and home caregivers. This essay argues how the almanacs acted as instruments of regulation of the female body, spreading ideals of femininity/virility, family, health, hygiene and national progress.

Keywords: Female body; Women's health; Pharmacy almanacs; Pedagogical device.

\section{Introdução}

Durante décadas, os "almanaques de farmácia" patrocinados, em suas origens, pelas antigas farmácias de manipulação e posteriormente por laboratórios que os empregavam para publicidade de seus produtos, foram onipresentes no cotidiano das famílias brasileiras, desempenhando papel expressivo no processo de modernização do País. Essas publicações, distribuídas gratuitamente pela indústria farmacêutica nacional emergente no fim dos oitocentos e consumida vorazmente pela população brasileira letrada nas cidades e no campo até meados do século XX, constituíram fonte importante de informação e entretenimento, bem como ferramenta de propaganda de novas práticas de saúde e consumo de medicamentos.

Os almanaques de farmácia da nossa Belle Époque veiculavam uma miscelânea de textos escritos e imagens cuja análise revela o estofo histórico-cultural e ideológico de que eram feitos. Como artefato de seu tempo, os almanaques eram atravessados por saberes, valores e imperativos 
que, embora dirigidos à saúde de seus leitores, ultrapassavam os propósitos mais imediatos de sua instrução, colaborando mais amplamente para a agenda higienista, civilizatória e modernizante em implementação no Brasil. Essa agenda envolvia, de um lado, encorajar novos comportamentos privados e públicos geradores de saúde, mas, sobretudo, produzir novos sujeitos para um mundo movido pela ciência e pelo ideal de progresso.

É possível acompanhar nesses almanaques seus esforços em disciplinar, educar e guiar os corpos e mentes de seus leitores, no sentido da obediência às práticas médicas legítimas que se firmavam, substituindo os velhos métodos populares de tratamento e cura. Mais evidente ainda é a relação dos almanaques com suas leitoras, o público privilegiado de seus discursos. As mulheres eram constantemente convocadas a cumprir os deveres de guardiãs da saúde de sua família, o que exigia, antes de tudo, o de cuidar da saúde e do bom funcionamento de seus próprios órgãos sexuais e reprodutivos. Tais artefatos participaram efetivamente do processo de medicalização dos corpos femininos e de sua sexualidade nos primórdios da República, quando ordem, disciplina e higiene pública tornam-se cruciais para o projeto nacional rumo à civilização.

Um desses almanaques de farmácia é o que levava o nome do medicamento produzido e divulgado por Daudt, Oliveira \& Cia. e que circulou por todo o território nacional entre 1904 e meados da década de 1970: d'A Saude da Mulher. Endereçado francamente às mulheres e divulgando um elixir que prometia regular o funcionamento dos ovários e úteros de suas leitoras, este almanaque permite analisar a produção discursiva hegemônica sobre a mulher, seu corpo e as relações de gênero nas primeiras décadas do século XX.

Neste artigo temos o objetivo geral de discutir aspectos da regulação, medicalização e pedagogização da mulher no Brasil da Belle Époque, a partir da análise de exemplares selecionados do Almanaque d'A Saude da Mulher. Mais especificamente, analisamos como esses almanaques podem ter operado na subjetivação das mulheres por meio de discursos hegemônicos sobre seu corpo, sexualidade e papéis sociais. A escolha desse almanaque para pesquisa dos mecanismos de regulação do corpo feminino à época justifica-se por ser essa publicação responsável por anunciar o medicamento mais popular da indústria nacional do período para os problemas "das senhoras", com larga difusão entre leitoras. Um exemplo disso é que, no ano de 1929, alcançou-se a marca de 2.500.000 exemplares distribuídos. Neste artigo, por razões de espaço, optamos por discutir alguns exemplares entre 1918 e 1946 que fazem parte de um corpus mais abrangente de pesquisa sobre a temática.

Na próxima seção, apresentamos uma breve revisão da literatura sobre os almanaques de farmácia e nossos fundamentos teóricos, argumentando principalmente sobre como atuaram como dispositivos de regulação social, servindo aos interesses de civilização e progresso da nação brasileira nas primeiras décadas do século XX. Em seguida, apresentamos o delineamento metodológico deste estudo e, posteriormente, relatamos e discutimos os resultados obtidos da análise dos exemplares selecionados desta pesquisa. Buscamos discorrer como o Almanaque d'A Saude da Mulher agiu como ferramenta de pedagogia feminina e mostrar certas estratégias de controle médicofarmacológico sobre o corpo da mulher no período, explorando o modo como as doenças "dos nervos" foram construídas a partir do conhecimento e regulação dos órgãos sexuais femininos.

\section{Molduras teóricas: os almanaques de farmácia como ferramenta civilizatória e reguladora}

Oriundos dos antigos almanaques europeus presentes no Brasil-colônia desde o século XVIII, os almanaques de farmácia começaram a circular em meados do século XIX, com seu apogeu entre 1930 a 1950, e ajudaram a disseminar o consumo de drogas medicinais e cosméticos, bem como noções e práticas de saúde e cuidado (Yasmim NADAF, 2011). Almanaques tais como Capivarol, Dr. Ayer, Dr. Richards, Biotônico Fontoura, Elixir Brasil, Pharol da Medicina, d'A Saude da Mulher, entre outros, distribuídos de forma gratuita em farmácias e drogarias, foram muito populares no País e somente começaram a perder força a partir da segunda metade do século XX, substituídos por novos meios de comunicação de massa emergentes.

Os almanaques de farmácia apresentavam características singulares que contribuíram para sua popularização: eram publicados por laboratórios farmacêuticos e utilizados como suporte publicitário; sua distribuição era gratuita e aceitavam cartas de leitores, que se tornavam coautores das publicações (Roger CHARTIER, 1998). O sucesso dos almanaques deveu-se, entre outras razões, à sua ampla penetração nos lares - tanto na cidade como nas áreas rurais com menor oferta cultural - e ao seu formato atraente, com ilustrações, calendários, horóscopos, anúncios diretos de medicamentos, cartas de pessoas supostamente curadas por seu uso, temas diversos relacionados à história, religião, literatura e ciência, entre outros conteúdos. Os almanaques mesclavam informação e entretenimento, propaganda direta e crônica cotidiana, exercendo um papel pedagógico e ideológico significativo na esfera da produção e disseminação de saberes e práticas sobre higiene, saúde e beleza (NADAF, 2011 ; Mario GOMES, 2006; Vera CASA NOVA, 1982). 
Com efeito, os almanaques de farmácia operavam como uma ferramenta civilizatória e um dispositivo regulador, influenciando os comportamentos dos leitores de ambos os sexos, incitando à compra de seus xaropes e pílulas, aconselhando quanto às normas de conduta e disseminando os novos discursos modernizantes que espelhavam a cultura europeia no País e espalhavam a ciência da época entre a população pouco letrada. Gradativamente, os conhecimentos científicos adentravam os lares, substituindo as antigas práticas de medicina popular que haviam passado de geração em geração (CASA NOVA, 1996).

No Brasil, como ressalta Ana Paula Martins (2004), a grande maioria da população brasileira ficou sujeita a práticas não regulamentadas pela medicina pelo menos até o início do século XX, mantendo seus costumes e recorrendo a benzedeiros, curandeiros e parteiras. No início do novo século, os almanaques de farmácias desempenharam um papel importante de divulgação de conhecimentos científicos, pois atingiam pessoas com menor poder aquisitivo e aquelas sem acesso a livros ou médicos, que contavam com os almanaques como fonte de informação (CASA NOVA, 1996).

Como veículos de modernização, os almanaques ajudaram a disseminar ideais de progresso nacional mediante o discurso que enaltecia a fabricação e o consumo de medicamentos industrializados, orientados pela ciência químico-farmacêutica e médica da época. Atuando como componente do dispositivo pedagógico da nossa Belle Époque, seus conteúdos reforçavam certos saberes e minavam outros, adequavam comportamentos, ditavam regras de higiene, saúde e bemestar, formando sujeitos para os tempos modernos. Tais publicações, focando na saúde e na educação sanitária, especialmente nas primeiras décadas do século XX, representaram, portanto, ferramentas eficazes para a concretização dos ideários modernizantes que forçavam caminho no Brasil em seu projeto de incluir-se entre as nações desenvolvidas (Caroline LARA, 2016).

Ao considerarmos o almanaque de farmácia enquanto "dispositivo pedagógico", cabe antes assinalar o que entendemos por "dispositivo". Como conceitua Michel Foucault (1988), o dispositivo constitui um conjunto heterogêneo que engloba discursos, instituições, regulamentações, organizações, leis, medidas administrativas, enunciados científicos, proposições filosóficas, filantrópicas, morais; incluindo o que é dito e o que não é dito. Esse não dito é a relação do discurso com o poder, tratando-se de uma exterioridade com relação ao dito, não de um enunciado latente, subliminar. Para Eduardo Oliveira (2015), os dispositivos possuem "[...] a função de configurar corpos e almas e, também, fabricar populações para atenderem a uma determinada urgência histórica" (p. 91).

Por "dispositivo pedagógico", termo elaborado por René Schérer, apropriado das formulações de Foucault sobre o dispositivo, compreendemos um conjunto de linhas de força heterogêneas que tornam a existência do campo educativo possível, englobando discursos, pensamentos, instituições, arquiteturas, leis e ações administrativas, postulações científicas, códigos morais e religiosos (Silvio GALLO, 2015; Alexandre CARVALHO; GALLO, 2017).

Atuando na educação de cada leitor e inscritos na missão civilizatória nacional, o almanaque de farmácia tinha o objetivo de

[...] transformar o Brasil num território culto e imune das doenças endêmicas e epidêmicas. $O$ Brasil real, negativo, nem o governo, nem as indústrias farmacêuticas tinham de mostrar lá fora, ao capital estrangeiro. Assim, além de pedagógico, esses almanaques transformaram-se em agentes políiticos - de civilização e de progresso -, cujo entorno, além do entretenimento, era divulgar regras de higiene, de saúde e de beleza (NADAF, 2011, p. 113).

Particularmente, os almanaques tiveram grande aceitação entre o público feminino, sendo muitos destinados especialmente às "senhoras". As mulheres que viviam no meio urbano liam os almanaques por modismo ou conveniência quando estavam nas farmácias; já as mulheres do meio rural faziam dessas publicações verdadeiros guias para o cotidiano, já que o acesso às escolas e às consultas médicas era mais restrito (CASA NOVA, 1996).

Acreditamos que os almanaques de farmácia, em sua difusão no Brasil, desempenharam papel considerável no complexo processo de medicalização dos corpos e da sexualidade, especialmente dos corpos femininos. O conceito de medicalização aqui adotado se inspira principalmente no sentido foucaultiano de biopolítica, isto é,

[...] a maneira pela qual o poder tende a se transformar, entre o fim do século XVIII e o começo do século XIX, a fim de governar não somente os indivíduos por meio de um certo número de procedimentos disciplinares, mas o conjunto dos viventes constituídos em população: a biopolíica - por meio dos biopoderes locais - se ocupará, portanto, da gestão da saúde, da higiene, da alimentação, da sexualidade, da natalidade etc., na medida em que elas se tornaram preocupações políticas (Judith REVEL, 2005, p. 26).

De fato, as transformações da sociedade europeia e também da brasileira no campo da governamentalidade durante o século XIX preparam o terreno para o processo de medicalização em seu sentido mais restrito e que se refere "[...] à impossibilidade de descrever experiências com 
o corpo humano que não passem, em algum sentido, pelo saber médico" (Rafaela ZORZANELLI; Francisco ORTEGA; Benilton BEZERRA JUNIOR, 2014, p. 1861). Este processo ocorre somente após a II Guerra, sendo objeto de reflexão de autores como Irvin Zola, Peter Conrad e Ivan Illich que, sob perspectiva crítica, revelam o forte processo histórico emergente nas décadas de 1950-1960, em que problemas de natureza não médica passam a ser formulados e tratados como problemas de ordem médica, frequentemente em termos de doenças e anormalidades.

A célebre frase "Pouca saúde, muita saúva, os males do Brasil são...", do personagem Macunaíma, de Mário de Andrade (1969), resume, em certa medida, a história da saúde pública do Brasil, principalmente na primeira metade do século XX, marcada pelo combate aos surtos epidêmicos nas áreas urbanas e às endemias rurais, como malária, doença de Chagas e ancilostomose ou amarelão, doença que ganhou repercussão nacional com o Folheto Jeca Tatuzinho, de Monteiro Lobato. Escrito por Lobato para o Laboratório Fontoura em 1924, baseado no seu Jeca Tatu, de Urupês (2007[1918]), o folheto tinha o objetivo de promover hábitos de saúde e higiene e anunciar medicamentos para várias doenças. Somente a partir da década de 1920, com a criação do Departamento Nacional de Saúde Pública, é que foi possível surgir um aparato estatal na área da saúde que centralizasse as ações sanitárias no âmbito federal.

Os almanaques de farmácia têm como antecedentes históricos as transformações na produção de medicamentos e práticas terapêuticas especialmente a partir do século XIX. É quando as farmácias e drogarias passaram paulatinamente a substituir as antigas boticas implementadas no período colonial por cirurgiões-barbeiros, jesuítas e boticários e que ainda teriam significativa difusão no território nacional ao longo dos oitocentos. No Brasil, na esteira das críticas lançadas ao caráter basicamente empírico das boticas, os primeiros cursos de farmácia emergem ainda na década de 1830, buscando regulamentar a ciência farmacológica e o exercício da profissão (Tania FERNANDES, 2004). Como afirma esta autora:

Até fins do século XIX as boticas ocupavam importante espaço na produção de medicamentos, sendo então substituídas por farmácias e pequenas indústrias. As farmácias manipulavam receitas médicas e comercializavam medicamentos industrializados. Já as pequenas indústrias, inserindo novas técnicas e fórmulas medicamentosas através do processo industrial de produção, dedicavam-se aos produtos compostos de extratos vegetais e minerais. O boticário, neste contexto, foi sendo substituído pelo farmacêutico, que já dispunha de formação profissional específica (p. 30-31).

Os almanaques de farmácia e suas fórmulas emergem, assim, já marcados pela retórica de cientificidade e modernidade que arrostava as ameaças de inconsistência e imprecisão dos meios de cura populares, conduzidos sem a devida formação técnico-científica. Nesse sentido, os almanaques que circulavam no País nas primeiras décadas do século XX podem ser concebidos como parte dos dispositivos biopolíticos vigentes em seu tempo para regulação das massas. Como afirmam Paula Gaudenzi e Francisco Ortega (2012),

[...] os estudos da medicalização se direcionam para a análise e insinuação da intervenção política da medicina no corpo social, por meio do estabelecimento de normas morais de conduta e prescrição e proscrição de comportamentos, o que tornaria os indivíduos dependentes dos saberes produzidos pelos agentes educativo-terapêuticos. Data do século XVIII, com o nascimento da medicina moderna e da Higiene, o início da intervenção médica na intimidade das pessoas, fazendo com que os profissionais da saúde e educadores, sobretudo, se tornassem especialistas a quem todos deveriam recorrer em busca de soluções para seus males domésticos (p. 2).

Com efeito, os novos saberes químicos e farmacológicos então em curso, aliados às modernas práticas no campo médico, institucionalizados pelos cursos superiores cada vez mais regulamentados, buscaram progressivamente deslegitimar as técnicas de saúde tradicionais. Trata-se do gradual fortalecimento da medicina moderna, com sua normatividade ubíqua que se concretiza, entre outros meios, por diretrizes, regras e recomendações repetidas e observadas no cotidiano. Esse novo conjunto de normas e diretrizes passou a nortear as condutas, fazendo-se penetrar, naturalizando-se nos discursos e práticas dos sujeitos (Guacira LOURO, 2008).

Nos almanaques d'A Saude da Mulher, essas normas se fazem ouvir na repetição incessante dos anúncios e noutros conteúdos aí veiculados que orientam o público - especialmente o público feminino - a adotar novos valores e práticas de saúde.

\section{Metodologia}

Este artigo, fruto de pesquisa de Mestrado em Psicologia da primeira autora, sob orientação da segunda autora e concluído em fevereiro de 2019, adota uma perspectiva discursiva crítica, de viés pós-estruturalista, que contextualiza sócio-historicamente os almanaques de farmácia como artefatos culturais singulares, circunscritos ao seu horizonte temporal, e que atenta, sobretudo, para as relações de poder aí envolvidas. Com base em exemplares colhidos do almanaque d'A 
Saude da Mulher, procedemos à análise e à interpretação de alguns conteúdos verbais e imagéticos que se destacam, sondando as relações de poder que permeiam seus discursos sobre a mulher, seu corpo, sua subjetividade e conduta. Os materiais colhidos foram interpretados à luz da revisão da literatura e das molduras teóricas adotadas, especialmente no que concerne ao arcabouço foucaultiano de dispositivo e dispositivo pedagógico.

Do total dos exemplares do almanaque d'A Saude da Mulher publicados entre 1918 e 1950 , reunidos durante a pesquisa, foram selecionados para este artigo os dos anos de 1918 , 1921, 1929, 1934, 1938 e 1946 que pudemos examinar na fase exploratória da investigação, entre números impressos obtidos no Instituto Histórico, Geográfico e Antropológico do Ceará e outros digitalizados disponibilizados gentilmente pela Profa. Yasmin Nadaf, estudiosa e colecionadora dos almanaques de farmácia. ${ }^{1}$ A análise dos exemplares aqui discutidos ocorreu entre janeiro e maio de 2018, em fase inicial da investigação.

Após obtermos acesso aos exemplares do almanaque, esses foram explorados inicialmente de forma livre, por meio de várias leituras flutuantes do material, de forma a conhecer o formato do almanaque, sua estrutura e os diferentes conteúdos divulgados, sem o compromisso imediato de sistematização dos dados. Nesse momento, foram registradas impressões gerais sobre o material e a linguagem empregada e analisados alguns temas emergentes para a discussão sobre a regulação da mulher e medicalização do seu corpo. Também foram levantadas tendências no tratamento de certos temas, regularidades quanto ao uso de certos repertórios linguísticos, potenciais efeitos de certas imagens e pistas para refinamento da pesquisa.

Cada exemplar foi analisado globalmente como unidade de análise temática, optandose por destacar os tópicos que mais diretamente se referissem ao problema da pesquisa e objetivos do estudo, ao longo das diferentes seções do almanaque, incluindo capa, anúncio de medicamentos, seções de entretenimento, carta de leitores, entre outras. Essa decisão resulta de uma triangulação entre questões do estudo, perspectiva teórica adotada e intuições das pesquisadoras diante do material explorado.

Na análise de cada exemplar, identificamos elementos verbais e imagéticos aludindo à conduta das mulheres e às relações entre os gêneros: corpo e sexualidade; papéis sexuais; entendimentos sobre feminilidade e masculinidade; prescrições morais e juízos de valor concernentes à boa ou à má conduta feminina; concepções sobre saúde e doença, especialmente das mulheres; diretrizes e imperativos endereçados à mulher para o cuidado de si e de sua família; recomendações e anúncios de medicamentos para consumo feminino, entre outros tópicos.

Em seguida à análise de cada exemplar, o conjunto de observações sistematizadas foi comparado em busca de certas regularidades e indícios sobre estratégias de regulação das mulheres nesse veículo. Particular atenção foi dada aos potenciais efeitos discursivos de tais estratégias na subjetivação das mulheres da época. A interpretação dos exemplares analisados e comparados deu-se à luz da literatura e dos quadros teóricos que sustentam este artigo.

\section{Resultados e discussão}

Destacamos a seguir os principais resultados da análise dos exemplares selecionados e consequente discussão, cotejando-os com a literatura revisada e o quadro conceptual empregado. Identificamos dois eixos temáticos centrais interligados que atravessam os almanaques, ilustrando como se revelam nos exemplares investigados.

\section{O Almanaque d'A Saude da Mulher e a pedagogia feminina}

Nos almanaques, a função pedagógica e de controle das mulheres pode ser observada de forma abrangente, desde os anúncios dos medicamentos, até os horóscopos de cada mês - os chamados "prognósticos", que descreviam o "belo sexo" e os padrões esperados de vida feminina. Como avalia Lara (2016, p. 14), as propagandas cumpriam sua principal função de "aconselhar e instruir" por meio de materiais textuais e imagéticos persuasivos. A linguagem eloquente das propagandas juntava-se à retórica convincente dos demais elementos dessas publicações, com grande potencial para orientação das condutas e subjetivação femininas.

Num dos "prognósticos", por exemplo, pode-se observar tal ação pedagógica na construção polarizada de expectativas de futuro entre homens e mulheres:

Os homens que nascerem neste mez serão de temperamento impetuoso, espírito fino e muito felizes nas armas, doptados das aptidões administrativas e amantes desportes. Farão um casamento de conveniencias que lhes trará fortuna e um lar agitado, pelas indisposições com a esposa. As mulheres serão delicadas e nervosas, amarão os poetas, casar-se-ão com

\footnotetext{
1 Os títulos do vasto acervo particular de almanaques de farmácia da professora Dra. Yasmin Nadaf podem ser acompanhados no sítio www.yasminnadaf.com.br. Agradecemos a professora por sua generosidade em permitir 0 acesso à sua coleção para a pesquisa, sendo este artigo um de seus resultados.
} 
comerciantes de drogas, de bom humor, e bastante stoicos para thes desculpar as suas predilecções estheticas [...] (ALMANAQUE D'A SAUDE DA MULHER, 1918, p. 7).

Os homens estão associados à virilidade (impetuosidade, pendor para as armas e aptidões de mando no trabalho). As mulheres são construídas como "delicadas e nervosas" e, de certo modo, ameaçadoramente sensíveis e românticas, pois "amantes de poetas". No caso das nascidas em fevereiro, esse problema será contornado por um marido bonachão e pragmático que perdoará essa inclinação da esposa para a fantasia. Para os homens bem-nascidos, a esfera pública dos negócios (e, imagina-se, da política); para mulheres dessa classe, a esfera privada do lar, do casamento (feliz ou infeliz), e do ócio preenchido com a arte e a poesia.

O medicamento "regulador do útero" $A$ Saude da mulher, que dá nome ao almanaque em estudo, é anunciado em linguagem direta e repetitiva, mediante imagens e textos em várias partes de cada fascículo. Além de matérias mais longas destinadas ao esclarecimento de suas bases científicas, o remédio também é divulgado mediante "cartas das leitoras" que o experimentaram e aparentemente se restabeleceram de suas suspensões, hemorragias, cólicas e outros achaques menstruais, dando seu depoimento favorável à droga. Também havia pequenas "chamadas" lembrando a eficácia do remédio e incitando as senhoras a não perderem tempo com outras medidas terapêuticas. "Minha Senhora, porque V. Excia. perde tempo usando para seus males remédios de efeitos desastrosos? Queira mandar buscar imediatamente A Saude da Mulher e terá a prova de sua eficácia. O essencial é não perder tempo" (ALMANAQUE D'A SAUDE DA MULHER, 1918, p. 18).

Na condição de discurso pedagógico, o Almanaque d'A Saude da Mulher aconselha, convence, convoca, repreende e, de forma gradual, conduz sua leitora, ensinando-a a ser mulher, saudável e adequada à sua sociedade. São lições provenientes da medicina, da ciência, da religião e das convenções sociais que são endereçadas ao corpo, à subjetividade feminina e à produção de certos modos femininos de ser e viver. A análise das ilustrações e os textos dos exemplares selecionados exploram temáticas diversas: cartas de agradecimento de senhoras ou de seus maridos pela eficácia do medicamento $A$ Saude da Mulher, códigos sobre conduta e polidez, alertas sobre doenças como a sífilis, lições de comportamento para as senhoras no lar e na maternidade, além de modas de vestuário feminino de inspiração europeia.

Os conteúdos do almanaque são reveladores

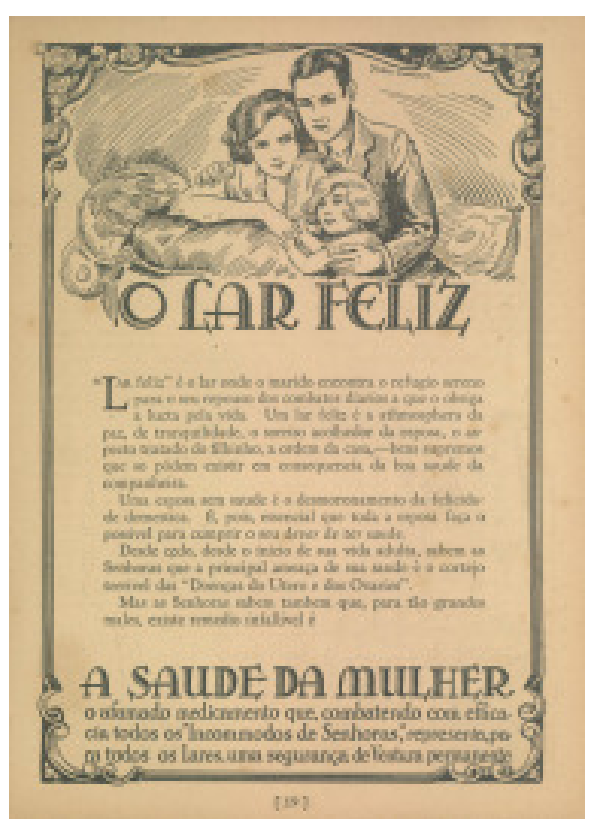
do interesse crescente pela mulher e pelas diferenças sexuais ao longo do século XIX, ensejando a disseminação de tratados e manuais médicos sobre a natureza feminina que veiculavam os conhecimentos específicos da obstetrícia e ginecologia. A Medicina e, em especial, as especialidades dedicadas à mulher $e$ à sua reprodução, conforme Fabíola Rohden (2001), haviam se convertido em uma verdadeira "ciência da diferença".

Imagem 1 - "O Iar feliz" (Almanaque d'A Saude da Mulher, 1929, p. 19)

\#PraTodoMundoVer Na imagem 1, "O lar feliz", extraída do Almanaque d'A Saude da Mulher (1929, p. 19), há um desenho de uma família tradicional, branca e bem-vestida, composta de pai, mãe e uma filha pequena, aparentemente sentada em um sofá, abraçada, no ano de 1929. A imagem não é colorida e não apresenta muitos detalhes ao fundo.

Nos exemplares analisados, a maternidade e o cuidado do lar deveriam ser a prioridade de toda boa esposa, o que requeria se manter com saúde, preservando suas funções reprodutivas e seu papel de responsável pela higiene e os bons costumes de sua família. A imagem 1 é seguida do texto:

'Lar feliz' é o lar onde o marido encontra o refugio sereno para o seu repouso dos combates diarios a que o obriga a lucta pela vida. Um lar feliz é a athmosphera da paz, de tranquilidade, o sorriso acolhedor da esposa, aspecto tratado do filhinho, a ordem da casa, - bens supremos que só podem existir em consequencia da boa saude da companheira. Uma esposa sem saude é o desmoronamento da felicidade domestica. É, pois, essencial que toda a esposa faça o possível para cumprir o seu dever de ter saude. Desde o inicio de sua vida adulta, sabem 
as Senhoras que a principal ameaça de sua saúde é o cortejo terrível das 'Doenças dos Uteros e dos Ovarios [...].

No novo mundo das famílias burguesas, onde as mulheres passavam a "guardiãs morais das famílias" (MARTINS, 2004), os almanaques ajudavam no monitoramento da sexualidade feminina e das suas funções reprodutivas de modo que viessem a desempenhar bem seus papéis de boas esposas, mães e donas de casa. Imperativos de saúde e bem-estar eram dirigidos às mulheres que deviam se desdobrar para preservar sua própria saúde e a de sua família, e como consequência, garantir a saúde geral, o vigor e o progresso da nação brasileira (CASA NOVA, 1996). No contexto de limitada "profilaxia urbana" e de desafios na "cruzada do saneamento da raça", o exemplar de 1921 do almanaque, por exemplo, incita a população, e em especial as suas leitoras, sobre o "dever, que cada um tem, de combater a syphillis" (ALMANAQUE D'A SAUDE DA MULHER, 1921, p. 31) e de cumprir as ordens da Saúde Pública como um modo de exercer o patriotismo e de colaborar com o crescimento do País. No exemplar de 1938, a propaganda de Nutrion, "o fortificante admirável", é usada para abordar, em retórica patriótica, a saúde dos escolares e a necessidade de os transformarem em homens fortes e saudáveis: "Os escolares de hoje serão o Brasil de amanhã. Não um paiz de gente fraca, doente e rachitica, mas uma nação de homens vigorosos, saudáveis e alegres" (p. 6).

O discurso dos exemplares revela um dispositivo pedagógico atuante que inclui, entre outros elementos heterogêneos, as relações maritais heterossexuais e o binarismo de gênero, a ciência médica e seus especialistas, os manuais e almanaques de difusão científica e propaganda medicamentosa e seus editores, além dos próprios remédios produzidos pela indústria farmacêutica a serem consumidos pelas leitoras aprendizes.

A partir de sua matriz patriarcal, o discurso dos almanaques reforça, a todo instante, os papéis tradicionais de gênero, com claras distinções entre a natureza do homem e a da mulher, bem como as normas gerais de conduta esperadas de cada um. É pela voz masculina dos doutores - que não somente davam nome a almanaques e remédios, mas também os fabricavam, transmitindo os conhecimentos produzidos pela ciência androcêntrica - que a normatividade sexual e de gênero se difundia entre os leitores e leitoras dessas revistas. Inclusive, nos divertidos prognósticos mensais, transparecem as normas de conduta sexual vigentes e as censuras lançadas às mulheres que não as respeitassem apropriadamente. No prognóstico de março de 1918 do Almanaque d'A Saude da Mulher, vaticina-se que "[...] as mulheres serão bonitas, românticas, pernósticas, sempre com muitos Romeus, mas nunca hão de casar [...] Vocação acentuada para o bandolim e para o suicídio a veneno" (p. 9). Por outro lado, um futuro mais feliz seria reservado às mulheres mais submissas ao papel feminino convencional.

No prognóstico de maio desse mesmo ano, prevê-se que as mulheres seriam recatadas, inimigas de festas, "[...] possuidoras de um coração de ouro, mas de uma formosura commum. Cedo encontrarão marido, a quem proporcionarão as grandes venturas de um lar exemplar. Seus filhos, muito bons, as ampararão na viuvez aos 60 annos" (ALMANAQUE D'A SAUDE DA MULHER, 1918 , p. 13). Recato, casamento e lar exemplar representam, no almanaque, a felicidade possível para as mulheres. As mulheres que se desviam das normas - festeiras, fúteis, frívolas, excessivamente vaidosas, indolentes, volúveis ou inclinadas à "morbidez de amores místicos" e a "amar poetas" são ameaçadas sutilmente com o celibato, o suicídio ou velhice desamparada e, se casadas, diretamente responsabilizadas pela desgraça de seus maridos.

Com efeito, o discurso patriarcal dos almanaques contribuía para a celebração das mulheres educadas com esmero e "criteriosas" como chave para o lar e o marido felizes. Condutas femininas desviantes tendiam a ser associadas duplamente à condição nervosa e a escolhas morais inadequadas.

Aqui empregamos o termo "discurso patriarcal" em referência genérica aos princípios do patriarcado, usualmente entendido como forma de organização social na qual homens chefiam a família e seus descendentes e detêm institucionalmente a autoridade nas demais esferas da sociedade, com base no pressuposto da superioridade masculina (Christine DELPHY, 2009). O patriarcalismo justifica, assim, a dominação das mulheres. Supõe que figuras de autoridade masculina não apenas têm poder de mando, mas desempenham um papel protetivo sobre as mulheres e outros subalternos sob a alegação de que cuidam de seus interesses, embora não levem em consideração seus desejos e opiniões.

O discurso médico do período, que dá apoio aos almanaques de farmácia, fomenta a criação de

[...] uma imagem moralmente superior da mulher se o seu corpo cumprisse as funções sociais do casamento, da maternidade e da educação dos filhos, mas se a mulher não controlasse seus desejos e se entregasse ao mundanismo e ao desregramento, facilmente ultrapassaria a tênue fronteira entre a normalidade e a patologia, como tão incansavelmente os médicos vão alertar ao abordar temas como masturbação e prostituição (MARTINS, 2004, p. 41). 
Nesse contexto de controle médico, em que crescia o número de publicações, como manuais e teses médicas, bem como a indústria farmacêutica no início do século XX, os almanaques também atuaram como importantes dispositivos de regulação e poder, posicionando a mulher, seu corpo, sua sexualidade e sua natureza "nervosa" em locais estrategicamente determinados.

\section{Úteros, ovários e mulheres nervosas: o controle médico- farmacêutico da Belle Époque}

No discurso do almanaque, são focalizadas as "fragilidades" naturais do corpo feminino, associando-se diretamente o estado uterino à saúde mental das mulheres. Na modernidade, o útero, como nos diz Mary Del Priore (1999), passa a centralizar as preocupações no campo da saúde feminina, não somente em termos de bem-estar físico, mas também como critério regulador da saúde mental da mulher. A então limitada compreensão sobre o corpo feminino, sujeito às oscilações menstruais, levava à difusão da mulher como física e mentalmente inferior ao homem

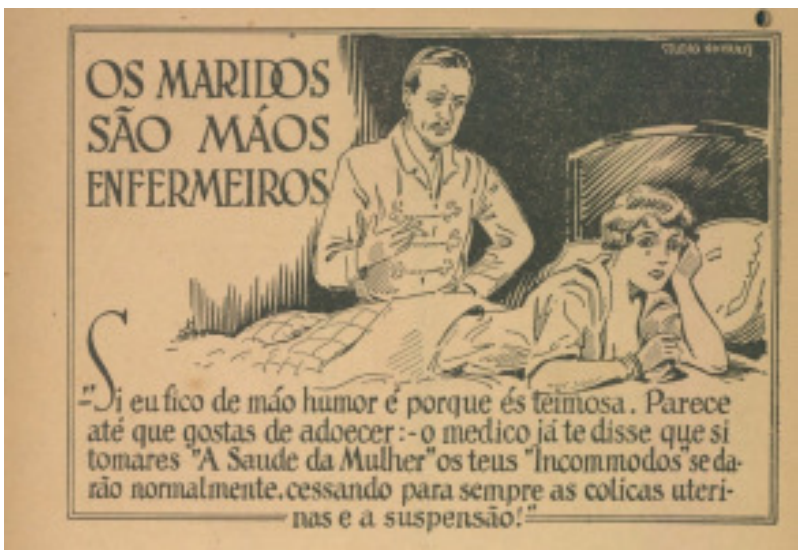
e submissa à sua fisiologia, portanto, alvo por excelência de intervenção médica. Também levava à crença de que males uterinos reverberavam em atribulações da alma feminina, vítimas da melancolia e outros transtornos do espírito como a histeria e a ninfomania.

Convocações dirigidas às mulheres para o cuidado constante de seus órgãos reprodutores aparecem nos exemplares, aliadas às críticas à sua eventual negligência com seu ciclo menstrual e à incitação ao consumo da medicação anunciada.

Imagem 2 - "Os maridos são máos enfermeiros" (Almanaque d’A Saude da Mulher, 1929, p. 44)

\#PraTodoMundoVer No exemplar de 1929, à página 44, o título irônico é "Os maridos são máos enfermeiros". Na parte central superior, há a imagem desenhada de um homem branco, de bigode, em pé, vestido em elegante robe de chambre, segurando um cigarro na mão direita e com a outra mão à cintura. Ele repreende sua jovem mulher à beira da cama no quarto do casal. A mulher, que é branca e bonita e está envolta por uma coberta, está deitada de bruços na cama, de costas para o marido, e chorando devido às cólicas menstruais. O marido queixa-se: "Si eu fico de máo humor, é porque és teimosa. Parece até que gostas de adoecer: - o médico já te disse que si tomares "A Saude da Mulher" os teus "Incommodos" se darão normalmente, cessando para sempre as cólicas uterinas e a suspensão!".

Um teor semelhante de responsabilização reaparece no exemplar de 1938, à página 9, no texto da propaganda do mesmo medicamento, intitulado: "7 dias de sofrimento cada mez só por ser mulher?". Abaixo do desenho de um rosto de mulher deitada, o narrador instrui sua leitora ao mesmo tempo que a censura por "imprevidência":

A Senhora não é, como pensa, uma pobre victima das injustiças da Natureza. Não, a Senhora sofre porque é imprevidente. Si é certo que o organismo feminino é de uma delicadeza extrema, exigindo cuidados permanentes para que funcione com regularidade, não é menos certo que a Sciencia põe ao alcance da mulher os meios adequados para corrigir as deficiências da Natureza (ALMANAQUE D'A SAUDE DA MULHER, 1938, p. 9).

Como nos diz Jurandir Costa (1989), a "mulher nervosa", vitimada por seus ovários e útero, tornou-se uma figura imprescindível ao poder médico. Medicando o nervosismo histérico, de "vapores" e de "palpitações", que viveu a mulher burguesa de fins do século XIX e começo do XX, o médico mantinha a sexualidade feminina a serviço da higiene e do Estado. Assim, a higiene institucionalizou o nervosismo da mulher ao passo que institucionalizou a saciação sexual do homem.

É permeado por esse contexto, mais fortemente, que os médicos serão convocados a disciplinar os corpos através do projeto de higienização da sociedade. Nesse cenário, difundemse os saberes sobre a "natureza feminina", como conduzir sua educação, como "administrar" sua sexualidade e as implicações da menstruação para a saúde desse corpo que, por si, já "nascia" mais propenso às doenças.

Esses temas se tornaram muito presentes nos almanaques de farmácia, onde podemos acompanhar os conselhos e ensinamentos que domesticam o corpo da mulher. O texto presente no Almanaque de 1918 (p. 10) diz que A Saude da Mulher cura anemia de origem uterina, anemia 
oriunda da puberdade, perturbações menstruais que atuam sobre o sistema nervoso, corrimento, cólicas, debilidade e deslocações do útero, além de aliviar as dores do parto.

Ao se referirem aos incômodos das senhoras, os almanaques frequentemente se referem às "irregularidades comuns do seu sexo". No exemplar de maio de 1918, há uma carta enviada por uma Dona Candida de Menezes, segundo os fabricantes, louvando a eficácia do remédio $A$ Saude da Mulher e assegurando que se curou radicalmente de tais irregularidades com apenas quatro frascos. O remédio é alardeado como o grande produto brasileiro e "o mais eficaz" para transtornos menstruais, prometendo combater "todos os incômodos das senhoras", além de curar e fortificar (ALMANAQUE D'A SAUDE DA MULHER, 1918, p. 13).

Essas cartas-depoimentos das leitoras (e às vezes de seus maridos agradecidos) constituíam uma seção permanente no Almanaque d'A Saude da Mulher; no exemplar de 1921 (p. 2), afirmase que o tônico é o melhor remédio para doenças do útero em qualquer idade, alegando cerca de três mil atestados de senhoras sobre seus benefícios. Os fabricantes assinalam sua utilidade no início das funções genitais, para senhoras casadas ou moças solteiras, atacadas de hemorragias, corrimentos, menstruações dolorosas e até para as senhoras mais idosas, com sintomas histéricos, dores reumáticas, cólicas e outras perturbações.

Com efeito, a retórica da eficácia medicamentosa do almanaque prenuncia a consolidação de um novo tipo de prática médica que se radicalizará crescentemente a partir da segunda metade do século vinte. Como ressalta Elisabeth Vieira (2002), a medicina surge como saber científico no contexto historicamente determinado da formação da sociedade capitalista, no interior da qual se constituiu, de forma mais efetiva, o projeto de medicalização dos corpos.

De acordo com Roberto Machado et al. (1978), a transformação do objeto da medicina significa um deslocamento do foco da doença para a saúde, nascendo, desse modo, o controle das virtualidades, da periculosidade e a prevenção. À medida que o projeto de higienização se fortalece, passando do espaço público das cidades à interioridade das casas, o médico passa a ter, então, um papel social mais amplo, configurando-se como um planejador urbano, educador e guardião da moral e dos costumes. Em especial, o médico passa a guardião da saúde física e mental das mulheres.

Como mostram Barbara Eirenreich e Deirdre English (1973), a ciência e a prática médicas (e os saberes interligados que as sustentam) vêm atuando como umas das mais poderosas fontes de ideologia sexista e opressão das mulheres. No contexto estadunidense, entre o fim do século XIX e início do XX, o saber médico descrevia as mulheres mais abastadas como doentes ou inválidas e as mulheres pobres oriundas das classes trabalhadoras (muitas negras e imigrantes) como contagiosas, isto é, potencialmente adoecedoras para os homens e para a sociedade em geral. Debilidade e propensão a doenças uterinas eram descrições endereçadas por médicos principalmente às ociosas mulheres dos estratos sociais superiores, de tal forma que tais mulheres eram estimuladas a considerar seus ciclos menstruais e outros eventos cotidianos como ocasião para o colapso físico e mental e para se comportar como "nervosas".

Por outro lado, mulheres empobrecidas, consideradas a princípio "naturalmente" saudáveis e talhadas para o trabalho braçal e para as longas jornadas, eram construídas como ameaça à saúde pública enquanto constituíam as principais vítimas do escasso repouso e nutrição, de doenças infectocontagiosas e de complicações do parto. Malgrado as diferenças entre mulheres de classes altas e baixas, as funções reprodutivas de todas as mulheres eram vistas pela Medicina como inerentemente patológicas: a entrada da menina na puberdade, a menstruação (ou a sua ausência), a gravidez, o parto e a menopausa. Alguns dias a cada mês todas as mulheres férteis tornavam-se inválidas. Centro das atenções médicas, o corpo da mulher vai paulatinamente se tornando fonte de discriminação e de redução dos seus horizontes de ação e emancipação (EIRENREICH; ENGLISH, 1973).

A submissão da mulher aos seus órgãos genitais e a predisposição para as perturbações mentais são claras nos almanaques analisados. No Almanaque de 1921 (p. 16-17), ao promover o produto farmacêutico A Saude da Mulher como "o protetor das senhoras", a lista de afecções femininas abrange, num mesmo rol, as "flores brancas" e os corrimentos, as cólicas uterinas, as hemorragias, as suspensões, a escassez das regras, enfim, todas as doenças derivadas do funcionamento irregular do útero e dos ovários, inclusive os "sintomas histéricos" considerados oriundos de doenças que acometem o útero.

Está em operação nas práticas médicas desse período e, também, nesses almanaques, a atitude geral de sondagem que exige as ações de observar, penetrar e domar o corpo feminino como um território a ser descoberto. Também se faz presente uma autocompreensão dos médicos e seus colaboradores como agentes responsáveis pelo processo de conhecimento-descobrimento de tais territórios e de intervenção neles (MARTINS, 2004).

O controle médico-farmacêutico da mulher burguesa no Brasil da Belle Époque implica o papel expressivo da ciência ginecológica em desenvolvimento, com sua ênfase na diferença sexual (ROHDEN, 2001), mas também o da Psiquiatria, especialidade médica reconhecida e 
institucionalizada a partir das duas últimas décadas do século XIX. Como a etiologia sexual estava na origem de todas as doenças mentais das mulheres, ginecologistas e psiquiatrias não apenas encontraram as causas de manias, psicoses, histeria, melancolia e tantas outras patologias nos corpos femininos, como defenderam que a cura ou o alívio dos sintomas para os casos mais graves demandavam terapêuticas ginecológicas (MARTINS, 2010). Como diz a mesma autora (2010), “[...] psiquiatras e ginecologistas desempenharam um importante papel nas estratégias de normalização e de marginalização das mulheres, mesmo que para isto precisassem alterar seus corpos e dobrar suas vontades" (p. 18).

A relação entre a etiologia sexual e as doenças das mulheres atravessa os exemplares estudados. Quase sempre essa associação era feita nos anúncios do preparado milagroso $A$ Saude da Mulher, em que perturbações menstruais e nervosas, fraquezas e anemia eram colocadas como sintomas comuns do sexo feminino, exigindo intervenção medicamentosa.

\section{Imagem 3 - "Coisas da vida" (Almanaque d'A Saude da Mulher, 1934, p. 29)}

\#PraTodoMundoVer A imagem mostra três desenhos de mulher, posicionados um abaixo do outro e à esquerda. As figuras de mulher são acompanhadas de textos dispostos à direita de cada uma. A primeira mulher, chamada Finóca, é jovem, branca e gorda e é retratada caminhando. Veste um vestido estampado de bolas, com gola branca arredondada e sem mangas que deixam ver seus braços roliços e ressaltam o volume de seu busto e barriga. Usa um pequeno chapéu preto que emoldura seu rosto redondo e pequenos sapatos pretos de salto. Na mão direita, leva um pacotinho quadrado e na mão esquerda um livro e um guarda-chuva fechado. A segunda mulher, chamada Izaltina, é desenhada de perfil e com a boca aberta, como se estivesse gritando com alguém. É jovem, branca e delgada, veste um vestido com estampas geométricas e de mangas curtas e sapatos pretos de salto alto. A mão direita apoia-se na sua cintura e a outra aponta agressivamente para alguém que não aparece no desenho. A terceira mulher, chamada Lucrécia, é uma mulher branca, de meia idade, muito magra, que está parada ao lado de seu cãozinho branco. Veste um longo vestido preto que realça a sua magreza e sua idade avançada. Leva uma mão à cabeça e parece sentir dor. Na outra mão leva um frasco de remédio.

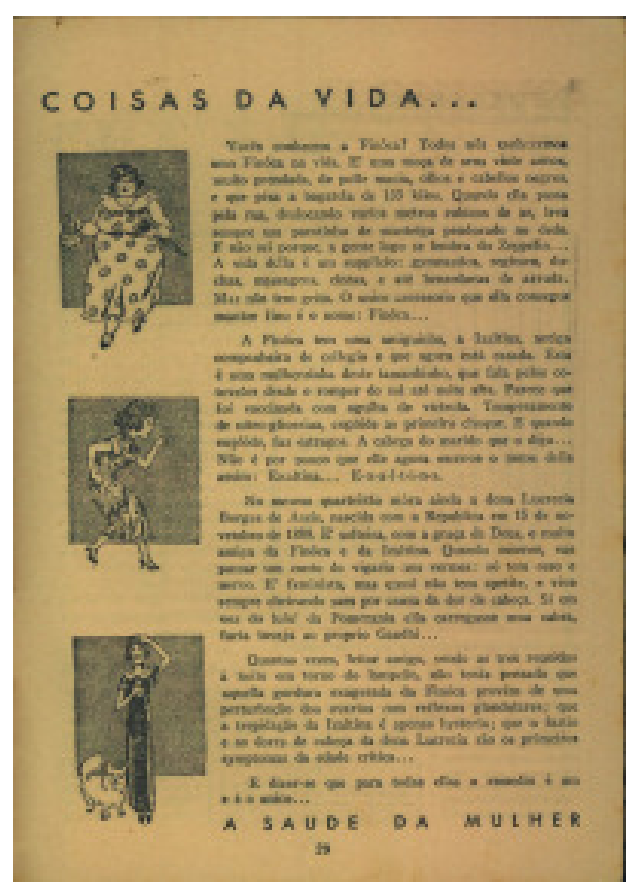

No exemplar de 1934 (p. 29), o anúncio do regulador vem numa seção de propaganda intitulada "Coisas da vida..." (Imagem 3), trazendo uma sequência de três desenhos de mulher, representando as diferentes idades e distúrbios femininos. A primeira é uma jovem gorda (apelidada de Finóca), de vestido de bolinha e chapeuzinho, levando (como diz o próprio texto), um "pacotinho de manteiga pendurado no dedo". Seu problema é a obesidade que a leva a tentar regimes, ginástica e outras estratégias para emagrecer, mas sem sucesso. A segunda, chamada de Izaltina, é desenhada de perfil, com uma mão à cintura e outra com o indicador em riste, como se discutisse com alguém. Esta, uma mulher "histérica" típica, é assim descrita:

A Finóca tem uma amiguinha, a Izaltina, antiga companheira de collegio e que agora está casada. Esta é uma mulher deste tamaninho, que fala pelos cotovelos desde o romper do sol até noite alta. Parece que foi vaccinada com agulha de victrola. Temperamento de nitroglicerina, explóde ao primeiro choque. E quando explóde, faz estragos. A cabeça do marido que o diga... não é por pouco que elle escreve o nome della assim: Exaltina... E-x-a-l-t-i-n-a. [...] a trepidação da Izaltina é apenas hysteria....

Por fim, a terceira, Dona Lucrecia, é apresentada como uma velha senhora, solteira e muito magra ("só osso e nervo"), de modos antiquados, trazendo na coleira seu cãozinho. Seu problema é a falta de apetite e a eterna dor de cabeça que lhe obriga a constantemente cheirar seus "sais", distúrbios associados à fase posterior à menopausa. Com efeito, noutros exemplares, como no de 1938, o elixir promete cura às "matronas", "para combater os males da edade crítica e seu longo séquito de rheumatismos, affecções hystericas, cólicas e distúrbios nervosos” (p. 17).

Nos textos do almanaque, todo o ciclo de vida da mulher é alvo de medicalização, apresentada como a serviço da felicidade feminina e, consequentemente, da felicidade da família e da sociedade. Na imagem 4, abaixo, extraída do exemplar de 1934, a sequência de cinco quadrinhos revela a construção da narrativa dominante do período sobre o destino da 
mulher e o papel do medicamento para seu "final feliz". Uma jovem recebe um convite de casamento; em seguida, se queixa de que todas as suas amigas estão se casando, e somente ela está ficando "pra semente". Depois constata que sua pele dá sinais das irregularidades que mensalmente a "envelhecem". Segue sua descoberta num jornal do anúncio do regulador $A$ Saude da Mulher e de uma de suas máximas: "só é bella de facto a mulher que tem saude". O quadrinho final ("Mezes mais tarde") mostra duas mulheres, em primeiro plano, numa cena de casamento, dialogando sobre a noiva de véu e grinalda com seu noivo, ao fundo: " - Como Lila está bonita! - É mesmo. Ella remoçou de uns tempos para cá!”.

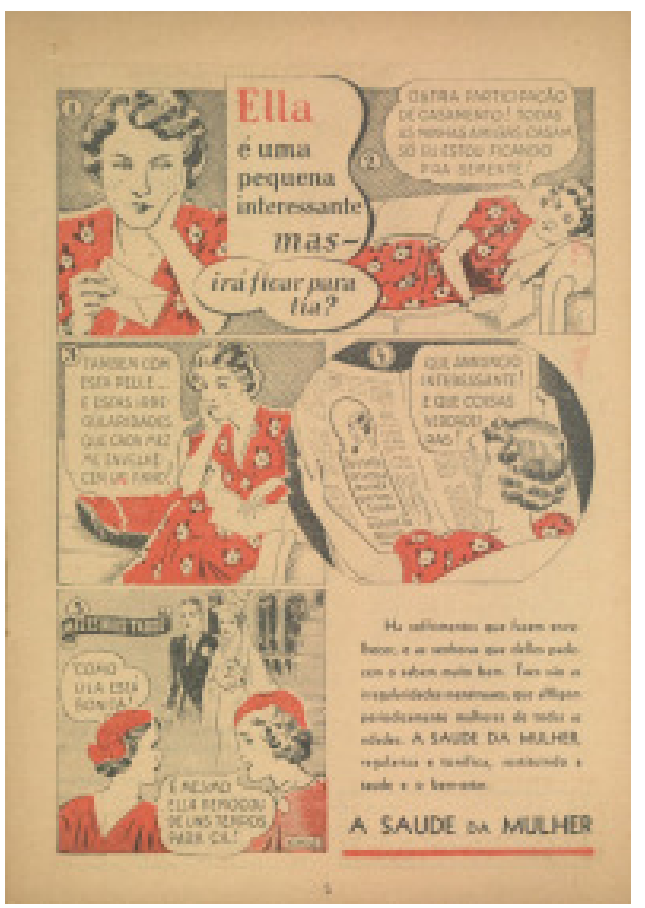

Imagem 4 - "Ella é uma pequena interessante mas irá ficar para tia?" (Almanaque d'A Saude da Mulher, 1934, p. 29)

\#PraTodoMundoVer A imagem é formada por cinco desenhos de uma mulher jovem, em formato de quadrinhos. No primeiro, uma moça branca, de cabelos curtos e vestido vermelho florido segura um envelope fechado contendo um convite. Tem uma mão no queixo e parece séria e preocupada. No próximo, ela está deitada num sofá, segura o convite aberto e, escrito num balão, se lastima de que suas amigas estão casando e ela não. Na imagem seguinte, ela está sentada no sofá, segurando o convite lido e com a outra mão no queixo em atitude reflexiva. Atribui sua condição ao mau estado da sua pele e aos distúrbios menstruais que a envelhecem. No quarto quadrinho, ela está de costas, sentada e lendo um jornal onde aparece um anúncio do regulador Saúde da Mulher que chama sua atenção. No último, ao fundo, ela aparece numa igreja, vestida de noiva no seu cortejo nupcial, de braços dados com seu noivo. Em primeiro plano, aparecem duas mulheres também jovens, de chapéu e bem vestidas, convidadas do casamento, que comentam uma para outra sobre como a noiva aparenta estar mais jovem e bonita.

Além do alerta às noivas para que não descuidem de sua saúde e, deste modo, de preparar um "futuro feliz para a família que vão fundar" (ALMANAQUE SAÚDE DA MULHER, 1946, p. 7), vemos também com frequência anúncios de preparados indicados para as mulheres grávidas e nutrizes obrigadas a se fortalecerem para alimentar dois organismos. No almanaque Guia da Saúde (GUIA...,1902), as mulheres grávidas e as que amamentam são exortadas em nome da ciência moderna a não se deixarem emagrecer e definhar sob pena de tornar estéril sua "dedicação materna": "Oh! Mães! A sciencia moderna oferece-vos os meios de ocorrerdes às vossas precisões e às de vossas crianças" (p. 22-23). Na sequência, o Vinho de Baudon é apresentado como garantia de farto aleitamento.

Os almanaques de farmácia, sobretudo o d'A saúde da mulher aqui focalizado, revelam a forte aliança da mulher higiênica com os saberes e práticas das especialidades médicas e farmacológicas em ascensão, transmitidos e reforçados em tais veículos, e que incitavam às novas formas de tratar e prevenir as doenças, especialmente aquelas que afligiam o público feminino, alvo preferencial da intervenção médica.

\section{Considerações finais}

Compreendemos os almanaques de farmácia que circularam no País entre o fim do século XIX e metade do século XX como dispositivos que serviram, entre outros propósitos, para legitimar um conjunto de valores e papéis sociais dominantes na sociedade brasileira da Belle Époque que se modernizava e aspirava alcançar padrões civilizatórios próximos aos das sociedades mais avançadas de seu tempo. Tiveram grande importância no processo de disciplinamento e medicalização de indivíduos e coletividades, além da disseminação da ciência e de seus métodos. Utilizando-se de anúncios, discursos médicos, conselhos, depoimentos, informações gerais e entretenimento, tornaram-se "livros de cabeceira" de muitas famílias. Os almanaques desempenharam funções de educar corpos e mentes, transmitindo códigos de conduta e orientando performances de gênero para seus leitores e leitoras. Tais publicações exibem um discurso pedagógico dirigido principalmente para as mulheres, que, como boas mães e esposas, deveriam ser responsáveis pelos cuidados físicos e morais de seu lar. 
Como mostra Louro (2008), "[...] a construção dos gêneros e das sexualidades dá-se através de inúmeras aprendizagens e práticas, insinua-se nas mais distintas situações, é empreendida de modo explícito ou dissimulado por um conjunto inesgotável de instâncias sociais e culturais" (p. 18). Trata-se de um processo detalhado, sutil, constante, inacabado. Família, escola, igreja, instituições legais e médicas são instâncias importantes nesse processo e, por muito tempo, suas orientações e ensinamentos pareceram absolutos, quase soberanos. Vivemos mergulhados em seus conselhos e ordens, somos controlados por seus mecanismos, sofremos suas censuras. As proposições, os discursos, os contornos delineados por essas múltiplas instâncias nem sempre são coerentes ou igualmente autorizados, mas estão espalhados por toda a parte e se constituem como potentes pedagogias socioculturais.

Os exemplares aqui estudados do Almanaque d'A Saude da Mulher participaram desse processo sutil de moldagem do gênero e da sexualidade. Em sua análise, foi possível perceber os mecanismos variados de produção e reprodução de determinados valores e narrativas de gênero, que vão desde as mensagens explícitas das capas (por exemplo, as imagens da mulher em seu papel convencional de mãe) até os textos dos "prognósticos", em que se exalta o comportamento sexual estabelecido e se censura a conduta desviante das mulheres. Nesses exemplares, a figura feminina ideal - mulher, esposa, mãe, guardiã da moral - é posicionada como frágil, obediente, dócil, recatada e, por sua natureza, está sujeita aos acometimentos comuns do seu sexo, como perturbações genitais, irregularidades menstruais, transtornos do útero e nervosismo histérico.

Mediante a utilização e apropriação dos saberes médico-farmacológicos sobre o corpo feminino e seus sintomas específicos, os almanaques de farmácia d'A Saude da Mulher foram ganhando espaço e confiança das leitoras brasileiras e ocupando sua intimidade. Os almanaques, com seus discursos fortemente entrelaçados à regulação do corpo feminino, como mostramos ao longo deste artigo, serviram, portanto, como importante instrumento de normatização heterossexual, mas também de disseminação de certos ideais burgueses de família, higienização dos corpos, pureza das mentes e grandeza da nação, representando uma ferramenta nada desprezível de manutenção da moral e dos "bons costumes".

Neste artigo, apresentamos os almanaques de farmácia d'A Saude da Mulher em suas dimensões pedagógicas, de medicalização e de regulação social, com especial foco no modo como os corpos femininos são construídos e educados nesses espaços. Sua análise ilumina o caráter agonístico, histórico e culturalmente situado de seu discurso, ajudando a desnaturalizar os saberes e práticas que definem o masculino e o feminino, o normal e o patológico.

Lembrando Simone de Beauvoir (2016), fazer-se mulher depende de inúmeros fatores, dos gestos, símbolos, comportamentos, dos gostos e dos desgostos vividos - aceitos ou contestados dia após dia. Tornar-se homem ou mulher é um processo cultural complexo, levado a cabo por diferentes meios. Esses almanaques produziram e reforçaram conhecimentos acerca da natureza feminina e colaboraram, ao longo de mais de sete décadas de publicação, para as formas de experiência do corpo e os modos de ser mulher nas diferentes regiões do Brasil.

\section{Referências}

ANDRADE, Mário. Macunaiìma: o herói sem nenhum caráter. São Paulo: Martins Fontes, 1969.

BEAUVOIR, Simone de. O segundo sexo: a experiência vivida. Rio de Janeiro: Nova Fronteira, 2016.

CASA NOVA, Vera Lúcia. "Almanaques de Farmácia (1920...)". Cadernos de Linguística e Teoria da Literatura, n. 8, p. 53-65, 1982.

CASA NOVA, Vera Lúcia. Lições de almanaque: um estudo semiótico. Belo Horizonte: EDUFMG, 1996.

CARVALHO, Alexandre Filordi de; GALLO, Silvio Donizetti de Oliveira. "Defender a escola do dispositivo pedagógico: o lugar do experimentum scholae na busca de outro equipamento coletivo". Educação Temática Digital, Campinas, v. 19, n. 4, p. 622-641, 2017.

CHARTIER, Roger. A história cultural: entre práticas e representações. Lisboa: Difusão Editora, 1998.

COSTA, Jurandir Freire. Ordem Médica e Norma Familiar. Rio de Janeiro: Graal, 1989.

ALMANAQUE para 1918 d'A Saude da Mulher. São Paulo/Rio de Janeiro: Estab. Graph. Weiszflog Irmãos, 1918.

ALMANAQUE para 1921 d'A Saude da Mulher. São Paulo/Rio de Janeiro: Estab. Graph. Weiszflog Irmãos, 1921.

ALMANAQUE para 1929 d'A Saude da Mulher. São Paulo/Rio de Janeiro: Estab. Graph. Weiszflog Irmãos, 1929. 
ALMANAQUE para 1938 d'A Saude da Mulher. São Paulo/Rio de Janeiro: Estab. Graph. Weiszflog Irmãos, 1938.

ALMANAQUE para 1946 d'A Saude da Mulher. São Paulo/Rio de Janeiro: Estab. Graph. Weiszflog Irmãos, 1946.

DELPHY, Christine. "Patriarcado (teorias do)”. In: HIRATA, Helena; LABORIE, Françoise; LE DOARÉ, Hélène; SENOTIER, Danièle (Orgs.). Dicionário crítico do feminismo. São Paulo: EDUNESP, 2009. p. 173-178.

DEL PRIORE, Mary. "Viagem pelo imaginário do interior feminino". Revista Brasileira de História, v. 19, n. $37,1999$.

EIRENREICH, Barbara; ENGLISH, Deirdre. Complaints and Disorders: the sexual politics of sickness. Tacoma: Lunaria Press, 1973. Disponível em https://edisciplinas.usp.br/pluginfile.php/969738/ mod resource/content/1/Complaints\%20and\%20Disorders\%204.14\%20\%281\%29.pdf. Acesso em $18 / 0 \overline{4} / 2019$.

FERNANDES, Tania Maria. Plantas medicinais: memória da ciência no Brasil. Rio de Janeiro: FIOCRUZ, 2004.

FOUCAULT, Michel. História da Sexualidade l: a vontade de saber. Rio de Janeiro: Graal, 1988.

FOUCAULT, Michel. Vigiar e punir: nascimento da prisão. Petrópolis: Vozes, 2014.

GALLO, Silvio Donizetti de Oliveira. "René Schérer e a Filosofia da Educação: Aproximações". In: REUNIÃO NACIONAL DA ANPED, 37, 2015, Florianópolis. Anais... Florianópolis: FAPESP, 2015. p. 1-17. ISSN 2447-2808.

GAUDENZI, Paula; ORTEGA, Francisco. "O estatuto da medicalização e as interpretações de Ivan Illich e Michel Foucault como ferramentas conceituais para o estudo da desmedicalização". Interface-Comunic., Saúde, Educ., v. 16, n. 40, p. 1-14, 2012.

GOMES, Mario Luiz. "Vendendo saúde! Revisitando os antigos almanaques de farmácia". Hist. cienc. saúde - Manguinhos, v. 13, n. 4, p. 1007-1018, 2006.

GUIA... Almanach-Guia da Saude, Paris, [s.n.], 1902.

LARA, Caroline de. "Agora sou outro!": propagandas e educação sanitária nos almanaques de farmácia (1900-1945). 2016. Dissertação (Mestrado) - Programa de Pós-Graduação em História, Cultura e Identidades, Universidade Estadual de Ponta Grossa, Ponta Grossa, Paraná, Brasil.

LOBATO, Monteiro. Urupês. Rio de Janeiro: Globo, 2007[1918].

LOURO, Guacira Lopes. "Gênero e sexualidade: pedagogias contemporâneas". Pro-Posições, v. 19, n. 2, p. 17-23, maio/ago. 2008.

MACHADO, Roberto et al. A Danação da Norma: medicina social e constituição da psiquiatria no Brasil. Rio de Janeiro: Graal, 1978.

MARTINS, Ana Paula Vosne. Visões do feminino: a medicina da mulher nos séculos XIX e XX [online]. Rio de Janeiro: FIOCRUZ, 2004.

MARTINS, Ana Paula Vosne. "Um sistema instável: as teorias ginecológicas sobre o corpo feminino e a clínica psiquiátrica entre os séculos XIX e XX". In: WADI, Yonissa Marmitt; SANTOS, Nádia Maria Weber (Orgs.). História e loucura: saberes, práticas e narrativas. Uberlândia: EDUFU, 2010. p. 15-49.

NADAF, Yasmim Jamil. "Essas revistinhas que se chamam almanaques". Revista Ecos: Literatura, Língua e Imprensa, Cáceres, Mato Grosso, v. 10, n. 1, p. 131-138, jul. 2011.

OLIVEIRA, Eduardo Alexandre Santos de. "O conceito de dispositivo da sexualidade na obra Foucaultiana 'A vontade de saber'”. Kalagatos - Revista de Filosofia, Fortaleza, v. 12, n. 24, p. 89108, 2015.

REVEL, Judith. Michel Foucault: Conceitos essenciais. São Carlos: Claraluz, 2005.

ROHDEN, Fabíola. Uma ciência da diferença: sexo e gênero na medicina da mulher. Rio de Janeiro: Fiocruz, 2001. 
VIEIRA, Elisabeth Meloni. A medicalização do corpo feminino. Rio de Janeiro: FIOCRUZ, 2002.

ZORZANELLI, Rafaela Teixeira; ORTEGA, Francisco; BEZERRA JÚNIOR, Benilton. "Um panorama sobre as variações em torno do conceito de medicalização entre 1950-2010". Ciência e Saúde Coletiva (Impresso), Rio de Janeiro, v. 19, n. 6, p. 1859-1868, jun. 2014.

Beatriz Oliveira Santos (beatrizsantos.psc@gmail.com) é psicóloga graduada pela Universidade Federal do Ceará (UFC). Mestra em Psicologia (UFC).

Idilva Maria Pires Germano (idilvapg@gmail.com) é doutora em Sociologia. Professora Titular do Departamento de Psicologia da Universidade Federal do Ceará (UFC). Professora Permanente do Programa de Pós-Graduação em Psicologia da UFC.

\section{COMO CITAR ESSE ARTIEO DE ACORDO COM AS NORMAS DA REVISTA}

SANTOS, Beatriz; GERMANO, Idilva. "Regulação do corpo feminino no almanaque de farmácia d'A Saude da Mulher". Revista Estudos Feministas, Florianópolis, v. 28, n. 1, e57854, 2020.

\section{CONTRIBUIÇÃO DE AUTORIA}

Beatriz Santos - Concepção do manuscrito, coleta e análise dos dados, elaboração do manuscrito, revisão e aprovação da versão final do artigo.

Idilva Germano - Concepção do manuscrito, análise de dados, elaboração do manuscrito, revisão e aprovação da versão final do artigo.

\section{FINANCIAMENTO}

O presente artigo (referente a resultados de pesquisa de Mestrado) foi realizado com apoio da Coordenação de Aperfeiçoamento de Pessoal de Nível Superior - Brasil (CAPES) - Código de Financiamento 001.

\section{CONSENTIMENTO DE USO DE IMAGEM}

Não se aplica (Imagens de ampla divulgação e distribuídas gratuitamente).

\section{APROVAÇÃO DE COMITÊ DE ÉTICA EM PESQUISA}

Não se aplica

\section{CONFLITO DE INTERESSES}

Não se aplica

\section{LICENÇA DE USO}

Este artigo está licenciado sob a Licença Creative Commons CC-BY Internacional. Com essa licença você pode compartilhar, adaptar, criar para qualquer fim, desde que atribua a autoria da obra.

\section{HISTÓRICO}

Recebido em 22/06/2018

Reapresentado em 29/04/2019

Aprovado em 28/06/2019 